\title{
SIMULATION OF FULL-SCALE WASTEWATER TREATMENT BIOLOGICAL PROCESSES
}

\section{Elena Elisabeta Manea $^{1}$}

1 INCD ECOIND, 71-73 Drumul Podu Dambovitei Street, sector 6, zip 060652, Bucharest, estreitferdt@yahoo.com, Romania

\begin{abstract}
Predicting wastewater treatment plant's efficiency during extreme influent variations can be made by using modeling and simulation tools. The studied wastewater treatment plant's biological stage consists in two identical lines with biological phosphorous removal and nitrification-denitrification. The influent and effluent quality parameters were monitored for a plant with advanced biological wastewater treatment stage. Different fractionation models were considered and the simulations were developed using WEST software. ASM1temp and ASM3temp models were used, both being based on IWA's Activated Sludge Models and extended with temperature corrections. Compliance with the experimental data obtained from the wastewater treatment plant was met after the model's calibration.
\end{abstract}

Keywords: ASM, simulation, wastewater, WEST

\section{Introduction}

Evaluating the wastewater treatment plants optimization alternatives can be time-consuming and can have increased costs. Currently, in Romania, many wastewater treatment plants have to be upgraded in order to comply with the legislation stringent effluent quality requirements as their obsolete configurations do not allow carbon, nitrogen and phosphorus removal. By using modeling and simulation tools, multiple scenarios can be evaluated in short time and with reduced costs.

Extensive studies on using modeling and simulation tools have been developed in the past, focusing on the evaluation of the possibility of simulating the advanced biological wastewater treatment by using only the available monitoring data [1] or on developing a dynamic activated sludge model (ASM) to better describe the overall removal of organic substrate, quantified as chemical oxygen demand, from A-stage high rate activated sludge (HRAS) systems [2]. Obtaining results consistent with reality was possible by measuring the components of ASM1 within 68 days and including them in the wastewater treatment plant's model [3].

The study focuses on simulating the biological process in an existing wastewater treatment plant, following the necessary steps in order to obtain reliable results (model selection, calibration and validation). Starting from a validated plant-wide model, the response of the existing system to large variations in the influent (or weather) characteristics can be evaluated by modeling and simulation.

Other studies were previously developed to evaluate the applicability of full-scale plants operational data to the activated sludge models, and to evaluate the feasibility of setting up the WWTP model starting only from the typically available construction and operational data [4]. 


\section{Materials and Methods}

The studied wastewater treatment plant, situated in south-east Romania, treats municipal wastewaters with an average inflow of $12400 \mathrm{m3} /$ day and low organic load (fig.1.). The biological treatment process consists in two identical lines, with biological phosphorous removal and nitrification-denitrification reactors. Each line has a biological phosphorous removal tank of 450 $\mathrm{m}^{3}$, two anoxic tanks of $450 \mathrm{~m}^{3}$ each, an aerobic tank with a volume of $2750 \mathrm{~m}^{3}$, secondary clarifiers, internal and external recycles, with flow values of $1260 \mathrm{~m}^{3} /$ day and approximatively $6200 \mathrm{~m}^{3} /$ day respectively. In order to ensure the oxygen needs for the aerobic processes, a proportional integral controller is implemented with a dissolved oxygen set point of $2 \mathrm{mg} / \mathrm{L}$. Because of the insufficient data, validation of the model for biological phosphorous removal process was impossible and the study only focused on Chemical Oxygen Demand (COD), Total Kjeldahl Nitrogen(TKN) AND Total Suspended Solids (TSS) removal.

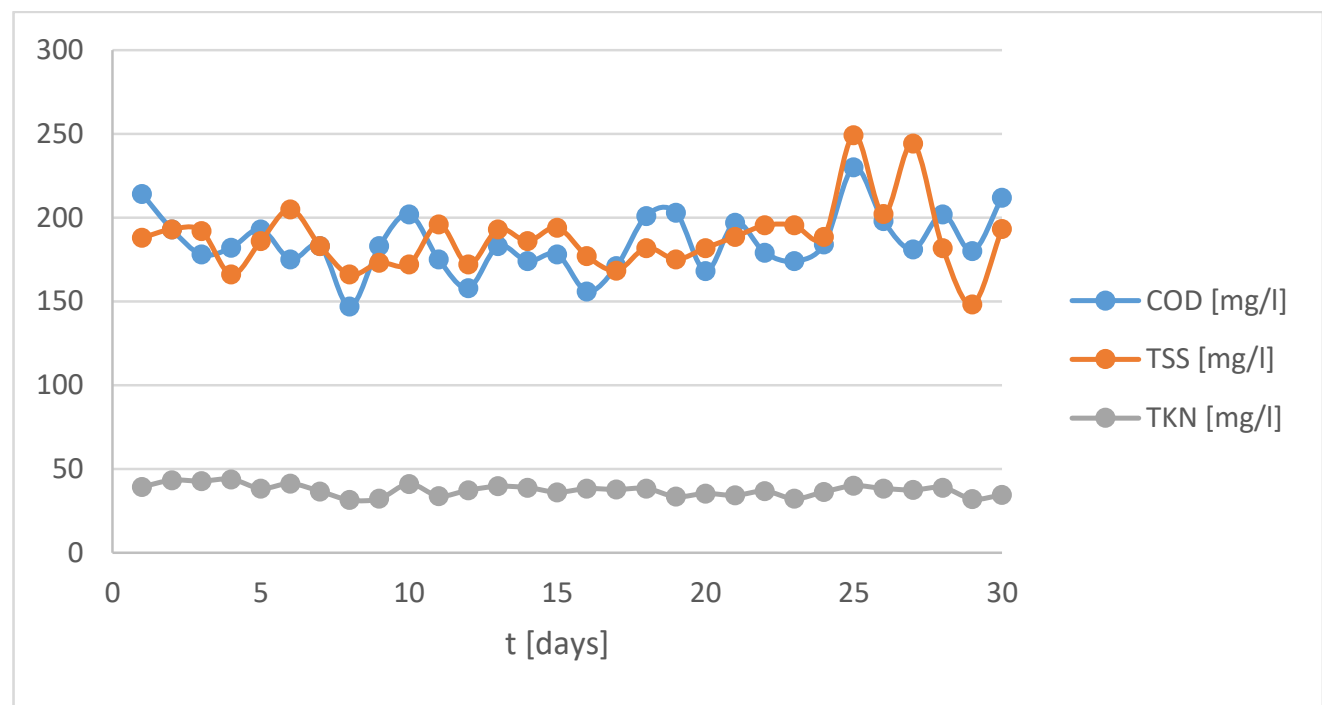

Fig. 1. Influent characteristics variation over 30 days

Starting from the available data on the plant characteristics, and influent and effluent loading, the wastewater treatment plant's configuration was implemented in WEST software (fig 2.).

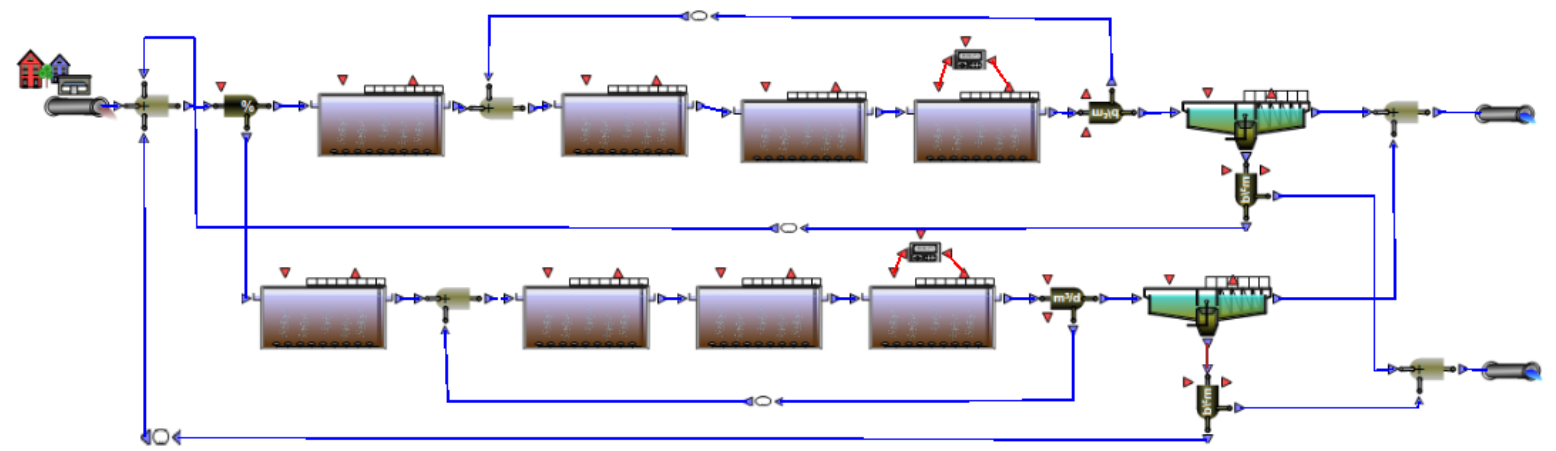

Fig. 2. Wastewater treatment plant's configuration

The models considered for the studied configuration were ASM1Temp and ASM3Temp. ASM1Temp is based on ASM1 (Activated Sludge Model No. 1, IAWQ) model published by the 
International Association on Water Quality (IAWQ) Task Group on Mathematical Modelling for Design and Operation of Biological Wastewater Treatment Processes [5]. The ASM1 model has been extended with temperature correction and ammonium limitation for aerobic and anoxic growth of heterotrophs. Temperature correction is the only difference between the classical ASM3 and ASM3Temp [6].

Another important factor that was taken into account was the considered influent fractionation model, since a detailed knowledge on the composition of influent going into the wastewater treatment system is essential for the development of a reliable model.

The COD in municipal wastewater is divided into 3 main fractions: non-biodegradable, biodegradable and active biomass. The non-biodegradable COD comprises non-biodegradable particulate, $X_{1}$, and non-biodegradable soluble, $S_{I}$. The biodegradable COD has the slowly biodegradable, $X_{S}$, and readily biodegradable, $S_{S}$, fractions. The active biomass consists of both heterotrophic, $\mathrm{X}_{\mathrm{H}}$, and autotrophic organisms, $\mathrm{X}_{\mathrm{AUT}}$ [7].

TKN fractions consist of: Snh - soluble ammonia nitrogen, Snd - soluble organic nitrogen, biologically degradable, Sni - soluble organic nitrogen, biologically non-degradable, Xnd particulate organic nitrogen, biologically degradable, Xni- particulate organic nitrogen, biologically non-degradable [8].

For any biological wastewater treatment plant simulation, the considered fractions can substantially influence the simulation results. Starting from the average values available in the literature [7-12], the fractionation model already available in WEST was updated, by lowering the biodegradable fraction of COD. The average TKN fractions for dry weather identified by Zawilski [8] were considered.

\section{Results and Discussion}

Using ASM1Temp, even after model parameters calibration based on the results of related research studies [12-15], the simulation results for the wastewater treatment process, showed a limited compliance with the monitored values (fig. 3.).

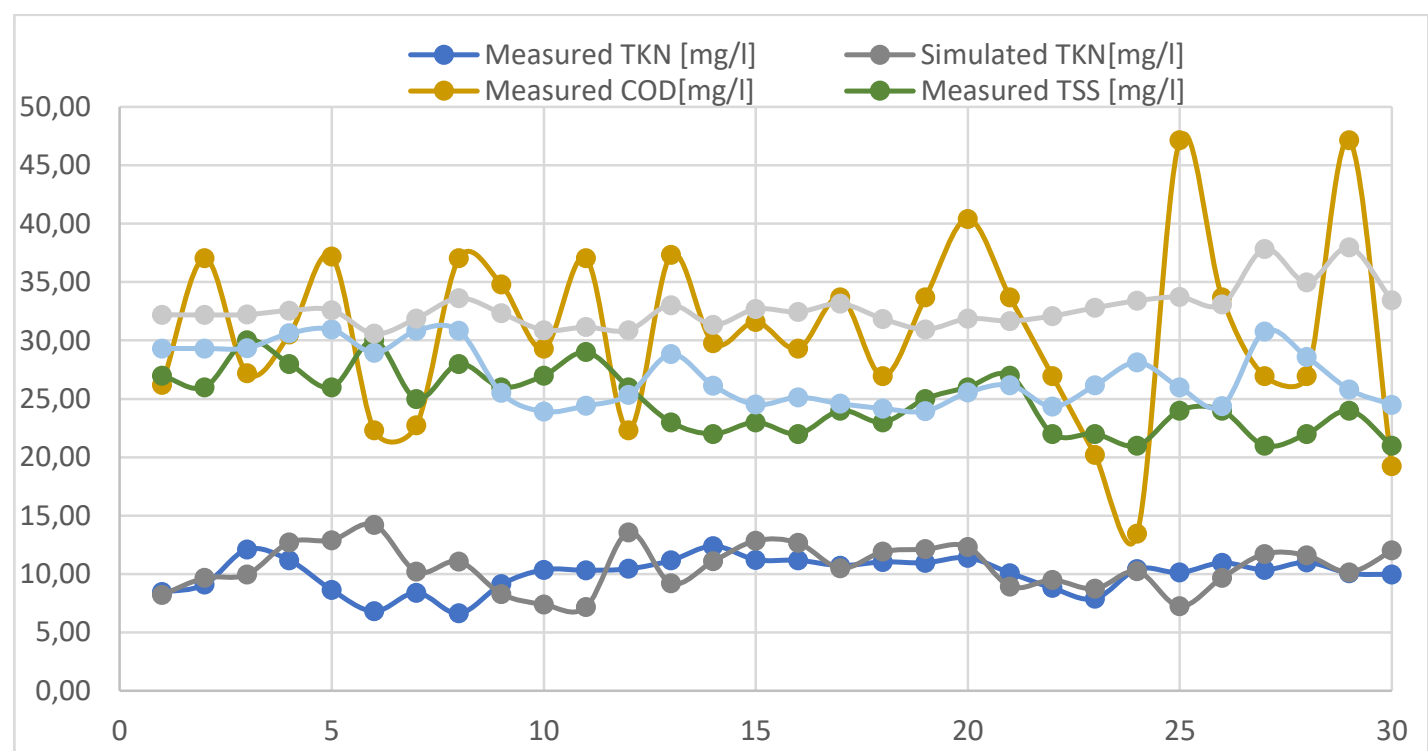

Fig. 3. Measured and simulated results for effluent COD, TKN and TSS, using ASM1Temp

The next set of results was obtained by applying the same calibration procedure when using ASM3Temp for simulating the wastewater treatment plant's biological stage (fig.4.). 


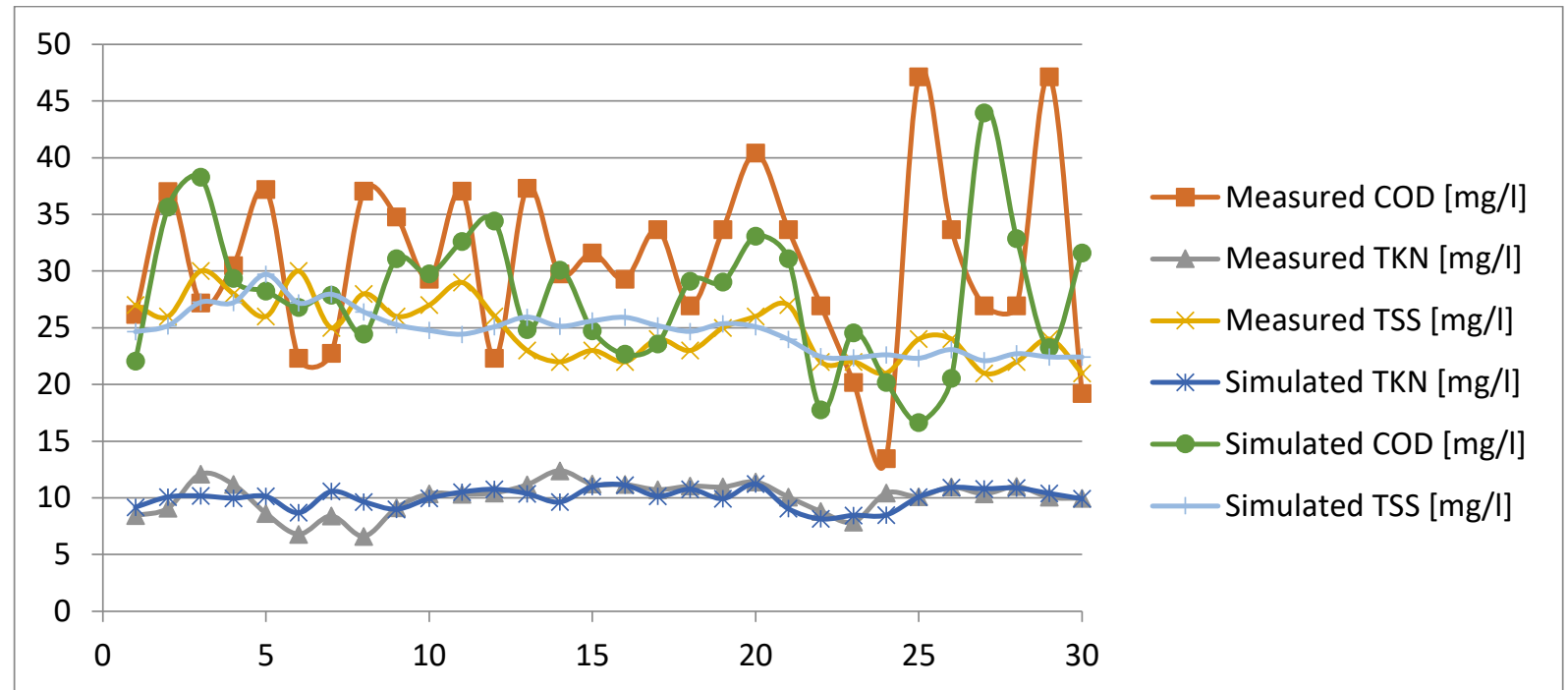

Fig. 3. Measured and simulated results for effluent COD, TKN and TSS, using ASM3Temp

When comparing the two graphs, it's obvious that the calibration procedure used for simulating the biological processes by using ASM3Temp was successful, and that for the studied case and parameters the right model to use is the latter one. Based on the results obtained from this study, simulations of the biological processes efficiency in different influent loading conditions and under multiple operational strategies can be developed.

\section{Conclusions}

The aim of the paper is to assess the possibility of using ASM1Temp and ASM3Temp models for simulating a fully-functional wastewater treatment plant, in order to create the possibility of evaluating optimization scenarios. In order to increase the certainty level in the results there is a need for extensive experimental research in the wastewater treatment plant's influent fractionation, aspect that would considerably enhance the accuracy of the simulation results thus facilitating the optimization process.

\section{Acknowledgements}

The author kindly acknowledges the support of ECOAQUA SA for providing detailed information on the wastewater treatment plant configuration, operating parameters and monitoring data.

\section{References}

[1] Marco F. (2015), A Pragmatic Approach to Wastewater Treatment Modelling: The Källby Wastewater Treatment Plant as a Case Study, MSc thesis, Lund University, Sweden

[2] Nogaj T. (2015), Mathematical modeling of carbon removal in the a-stage activated sludge system, PhD Thesis, University of Central Florida, United States of America

[3] Mohamadi F., Rahimi S., Bina B., Amin M., (2015) Modeling of Activated Sludge with ASM1 Model, Case Study on Wastewater Treatment Plant of South of Isfahan, in Current World Environment, Vol. 10(Special Issue 1), 96-105

[4] Sochacki A. , Knodel J., Geissen S.-U., Zambarda V., Bertanza G., Plonka L., Modelling and simulation of a municipal WWTP with limited operational data, available online at: https://www.kth.se/polopoly_fs/1.650929!/JPSU16p47.pdf

[5] Henze M., Grady C., Gujer W., Marais G., Matsuo T. (1987) Activated Sludge Model No.1. IAWPRC Scientific and Technical Report No.1. IAWPRC, London.

[6] DHI, (2012). WEST Models Guide 2012. 
[7] Wentzel M., Mbewe A., Ekama Ga. (1995) Batch measurements of readily biodegradable COD and active organism concentration in municipal wastewater, Water SA, Vol. 21 (2) 117-124.

[8] Zawilski M., Brzezińska A., (2009) Variability of COD and TKN Fractions of Combined Wastewater, Polish Journal of Environmental Studies, Vol. 18, No. 3, 501-505

[9] Melcer H., Dold P. L., Jones R. M., Bye C. M., Takacs I.,Stensel H. D., Wilson A. W., Sun P., Bury S., (2003). Methods for wastewater characterisation in activated sludge modelling. Water Environment Research Foundation (WERF), Alexandria, VA, USA

[10] Xu, S.; Hultman, B., (1996). Experiences in wastewater characterization and model calibration for the activated sludge process, Water Science and Technology, Vol. 33 (12), 89-98.

[11] Pasztor I., Thury P., Pulai J., (2009) Chemical oxygen demand fractions of municipal wastewater for modeling of wastewater treatment, International Journal of Environmental Science and Technology, Vol.6 (1), 51-56

[12] Mannina G., Cosenza A., Vanrolleghem P., Viviani G.,(2011) A practical protocol for calibration of nutrient removal wastewater treatment models, Journal of Hydroinformatics, no.13, iss.4, 575-595

[13] Marquot A.,(2006) Modelling nitrogen removal by activated sludge on full-scale plants: Calibration and evaluation of ASM1, PhD Thesis, Université de Pau et des Pays de l'Adour, France

[14] Gürkan S., (2004) Systematic calibration of activated sludge models, PhD Thesis, Ghent University, Belgium

[15] Petersen B., Gernaey K., Henze M., Vanrolleghem P.A.,(2003) Calibration of activated sludge models: a critical review of experimental designs, Biotechnology for the Environment: Wastewater Treatment and Modeling, Waste Gas Handling Volume 3C of the series Focus on Biotechnology, pp 101-186 